other micro-organisms used for vitamin assay is not determined.

This work forms part of an investigation on nutritional deficiencies carried out on behalf of the Air Ministry under the direction of Wing-Cmdr. T. F. Macrae; the author is a member of the Civilian Technical Corps.

Lister Institute, London, S.W.1.

Roland A. Coulson. Aug. 28.

${ }^{1}$ Coulson, R. A., Ellinger, P., and Holden, M., Biochem. J., 38, 150 (1944).

2 Jansen, B. C. T., Rec. trav. chim., 55, 1046 (1936). Hennessy, D. J., and Cerecedo, L. R., J. Amer. Chem. Soc., 61, 179 (1939).

' Najjar, V. A., and Ketron, K. C., J. Biol. Chem., 152, 579 (1944).

- Report by the Vitamin $B_{1}$ Sub-Committee of the Accessory Food Factors Committee of the Medical Research Council and the Factors Committee of the Medical Research

-Wang, Y. L., and Harris, L. J., Biochem. J., 33, 1356 (1939).

- Elvehjem, C. A., and Teply, L. J., Chem. Rex., 33, 185 (1943).

\section{Determination of Aneurin by the Thiochrome Method after its Uptake by Yeast}

For the determination of aneurin there are both chemical and biological methods. Among the former the thiochrome method is the most outstanding ${ }^{1}$. The biological methods are very tedious, and the error involved is considerable. For routine analysis, which necessitates the rapid attainment of a reliable result, the thiochrome method is the only one at present available. It involves the oxidation of the aneurin in alkaline solution to the fluorescent sub. stance thiochrome, the latter being extracted with isobutanol or amyl alcohol and determined in a fluorimeter. The aneurin often occurs to a large extent as phosphate esters, for example, cocarboxylase, the thiochrome derivatives of which are not soluble in isobutanol. The thiochrome method gives excellent results with pure aneurin solutions or, for example, extracts of compressed yeast. In the determination of aneurin in certain materials, however, such as cereal products (especially flours of high extraction, bran, etc.), urine, blood, milk or molasses, complications arise, since interfering substances are present which in the oxidized or unoxidized state have different fluorescent powers, or influence the oxidation of the aneurin itself to thiochrome. A number of modifications have already been described, which, however, to judge from the literature, are not altogether satisfactory.

These difficulties have been overcome by the following method which is based on the previous work of Sperber and Renvall ${ }^{2}$ and Sperber ${ }^{3}$, who have shown that aneurin is very readily taken up by baker's yeast, especially under aerobic conditions and in the presence of a substrate. It has been found in these investigations and in those of Westenbrink and coworkers ${ }^{4}$ that the aneurin in yeast occurs almost exclusively as pyrophosphate ester (cocarboxylase). This, however, is split up when the yeast is boiled; consequently the aneurin in the boiled extract is principally in the free form. Our procedure consists in shaking the material the aneurin content of which is to be estimated with baker's yeast, and afterwards determining the aneurin content of the extract obtained by boiling the yeast. Interfering factors present in the substance do not pass into the yeast extract.

Our investigations have shown that the capacity of the yeast for taking up aneurin is very great.
Under the conditions of our experiments $1 \mathrm{gm}$. of yeast took up $900-1,000 \mu \mathrm{gm}$. aneurin from flour extract in the course of one hour's shaking. The quantities of yeast necessary are therefore so small that allowance generally can be made for the aneurin content of the yeast itself by means of an average value (in our case $c .4 .5 \mu \mathrm{gm}$. $/ \mathrm{gm}$.). In general we shook 50-200 ml. flour extract, containing about 60-120 $\mu \mathrm{gm}$. aneurin, for ninety minutes at $25^{\circ} \mathrm{C}$. (water thermostat) in Fernbach flasks with $2 \mathrm{gm}$. compressed yeast. In the beginning our results proved to be too low, despite the fact that, after shaking, the substance no longer contained any aneurin. The explanation must be that the phosphatase, which during the heating of the yeast splits up the cocarboxylase and other phosphate esters to aneurin (see above), had been inactivated during the shaking.

In this connexion reference may be made to the investigations on the pyruvic acid metabolism in starved yeast and aerated yeast performed by Runnström and co-workers ${ }^{5}$. The metabolism of pyruvic acid added to a yeast suspension is strongly inhibited in such yeasts. The results of this work, which is to be resumed, made it probable that it is the decarboxylation of the pyruvic acid through the agency of the cocarboxylase that is affected by the starvation or aeration treatment. It is possible that in this case also the above-mentioned dephosphorylation of the cocarboxylase plays a decisive part.

Attempts to use 'Diastase Merck', which, according to Ritsert', contains sufficient phosphatase to split the cocarboxylase, gave results which were not fully satisfactory. When this method is employed, the yield of thiochrome from the oxidation of the aneurin is diminished. The procedure is, moreover, rather lengthy. We therefore tried to employ the phosphatase of the yeast, adding fresh yeast to the shaken material. This proved to be without effect. It proved possible, however, to dephosphorylate the cocarboxylase in the shaken yeast by adding cytolysed yeast to the previously boiled extract of the shaken yeast and reboiling. Repeated analyses of the same flour gave values with a standard deviation of $2 \cdot 6$ per cent.

Aneurin added to flour extract was recovered, and in the determination of a cocarboxylase preparation values were obtained which corresponded well with the results of Warburg determinations on the same material. The method of analysis described is also used for the estimation of aneurin in molasses and urine.

A detailed account of these investigations will be published elsewhere.

Cereal Laboratory,

R. Marcuse.

T. WIDHE.

'Tre Kronor' Flour Mill, Stockholm.

Wenner-Gren Institute for

Experimental Biology,

University of Stookholm. Aug. 21

1 Jansen, B., Rec. trav. chem., 55, 1046 (1936).

'Sperber, E., and Renvell, S., Biochem. Z., 310, 160 (1941).

${ }^{3}$ Sperber, E., Biochem. Z., 313, 62 (1942)..

"Westenbrink, H. K. G., van Dorp, D. A., Gruber, M., and Veldman, H., Enzymologia, 9, 73 (1940).

- Runnström, J., and Marcuse, R., Ark. f. Kemi, 18A, nr. 14 (Stock holm, 1944).

' Ritsert, K., Klin. Wochenschrijt, 1371 (1939). 